\title{
Deprivations, futures and the wrongness of killing
}

Don Marquis University of Kansas, Lawrence, Kansas, USA

\begin{abstract}
In my essay, Why abortion is immoral, I criticised discussions of the morality of abortion in which the crucial issue is whether fetuses are human beings or whether fetuses are persons. Both argument strategies are inadequate because they rely on indefensible assumptions. Why should being a human being or being a person make a moral difference? I argued that the correct account of the morality of abortion should be based upon a defensible account of why killing children and adults is wrong. I claimed that what makes killing us wrong is that our premature deaths deprive us of our futures of value, that is, the goods of life we would have experienced had we survived. This account of the wrongness of killing explains why killing is one of the worst of crimes and how killing greatly harms the victim. It coheres with the attitudes of those with cancer or HIV facing premature death. It explains why we believe it is wrong to kill infants (as personhood theories do not). It does not entail that it wrongs a human being to end her life if she is in persistent vegetative state or if her future must consist only of unbearable physical suffering and she wants to die (as sanctity of human life theories do not). This account of the wrongness of killing implies (with some defensible additional assumptions) that abortion is immoral because we were fetuses once and we know those fetuses had futures of value.

Mark Brown claims that this potential future of value account is unsound because it implies that we have welfare rights to what we need to stay alive that most people would reject. I argue that Brown is incorrect in two ways: a welfare right to what we need to stay alive is not directly implied by my account and, in addition, most of us do believe that dependent human beings have substantial welfare rights to what they need to stay alive. Brown argues that depriving us of a future of value of which we have mental representations both is a better explanation of the wrongness of killing and does not imply that abortion is immoral. I reply that (a) if Brown's arguments against my view were sound, those arguments could be easily adapted to show that his view is unsound as well and (b) Brown's view is both ambiguous and unsound on any interpretation.

The most popular class of pro-choice argument strategies appeals to the view that some or all fetuses lack either a mental state or function or a capacity for a mental state or function necessary for possession of the right to life. Desires, interests, sentience, various concepts, moral agency, and rationality have all been suggested as candidates for this crucial mental role. Brown's analysis is one member of this class of
\end{abstract}

strategies. I believe that it is possible to show that none of these strategies is reasonable. However, there are so many of these strategies that the required argument demands something more like a book and less like a short essay. The argument of the following essay is a piece of this larger argument.

(Fournal of Medical Ethics 2001;27:363-369)

Keywords: Abortion; future of value; Mark Brown; Don Marquis; the right to life; welfare rights

In my essay, Why abortion is immoral, I claimed that an argument we can call "a future of value argument" shows that typical fetuses have the right to life. ${ }^{1}$ The essence of the future of value argument can be set out schematically. Premise 1: Having a future of value is the basis for the right not to be killed. Premise 2: Fetuses have a future of value. Conclusion: Therefore, fetuses have the right not to be killed.

In a recent essay in this journal, Mark Brown argued that the future of value argument is unsound because of an equivocation on the concept of a future of value. ${ }^{2}$ On the one hand, "future of value" can refer to the potential future of value of a human organism. A human's potential future of value is the goods of life that a human being later would have experienced had her life not ended. On the other hand, "future of value" can refer to a selfrepresented future of value. A self-represented future of value is a human being's valuable future life as she presently represents it to herself. Brown argues that, on the one hand, if "future of value" is understood as "potential future of value", the second premise of the argument is true, but the first premise is false. Brown argues that, on the other hand, if "future of value" is understood as "self-represented future of value", the first premise of the argument is true, but the second premise is false. Thus, no version of the future of value argument is sound. Any plausibility the future of value argument may seem to have results from confusing the concept of a potential future of value with the concept of a self-represented future of value.

Let us call the two arguments Brown wishes to distinguish "a potential future of value argument" and "a self-represented future of value argument". Brown's view of the truth or falsity of the second premises of both arguments is clearly correct. The second premise of the potential future of value argument is true because, if fetuses are allowed to live, then the lives of the adults they will become 
contain the sorts of goods presently alive adults agree to be valuable to them. The second premise of the self-represented future of value argument is false because fetuses are neurologically incapable of representing their futures to themselves. Thus, whether or not Brown's appraisal of either version of the future of value argument is correct turns on whether the first premise of the potential future of value argument is false, as he maintains, and whether or not the first premise of the selfrepresented future of value argument is true, as he maintains. The purpose of this essay is to dispute both of these claims.

\section{Brown's argument against the potential future of value argument}

Clear discussion of Brown's views requires some distinctions. The first premise of the potentia future of value argument, which Brown wishes to reject, is a simplified version of my (surely incomplete) account of the wrongness of killing. Call this "the potential future of value account". The first premise of the self-represented future of value argument, which Brown wishes to accept, is essentially Brown's account of the wrongness of killing. Call this account "the self-represented future of value account".

Brown claims that an argument that appeals to our lack of welfare rights shows that the potential future of value account is false. Basically Brown's welfare rights argument comes to this: Premise 1: If having a potential future of value is the basis for the right not to be killed, then humans have a welfare right to what they need to stay alive. Premise 2: Humans do not have a welfare right to what they need to stay alive. Conclusion: Therefore, having a potential future of value is not the basis for the right not to be killed. ${ }^{3}$

Since many would claim that the right not to be killed and the welfare right to what one needs to stay alive (whatever its scope) are different rights, one wonders why Brown thinks that the first premise of this welfare rights argument is true. Here is his sole argument: "Someone who has been killed and someone who has been denied access to life support have been deprived equally of their potential futures." 3 Brown's claim is plainly true. But how is the first premise of his welfare rights argument supposed to follow?

There are good reasons for thinking it does not. Everyone else can honour their duty not to kill you by doing nothing at all. As a consequence, such a duty is often called a negative duty. If there is a welfare right to what one needs to stay alive, and one is dependent in some way, then at least one other person has a duty to do something to provide the needed assistance. As a consequence, such a duty is often called a positive duty. It follows that a welfare right to what one needs to stay alive (whatever its scope) is not strictly entailed by the right not to be killed, whatever one's account of the wrongness of killing. Of course, this does not at all rule out the possibility that the potential future of value account of the wrongness of killing (or some other account) could be combined with other defensible moral precepts to yield a welfare right to what one needs to stay alive, on at least some occasions.

The difficulty concerning the first premise of Brown's welfare rights argument can be seen in another way. Insisting that you honour my right not to be killed does not deprive you of anything to which you have a presumptive right, except, perhaps, your freedom. Insisting that you honour my right to what I need to stay alive can deprive you of your presumptive right to your property or your body. Thus, an important rights based argument must be ruled out to arrive at the welfare right to what one needs to stay alive that does not need to be ruled out to arrive at the right not to be killed. Accordingly, Brown's defence of the first premise of his welfare rights argument is insufficient.

Discussion of the second premise of Brown's welfare rights argument might seem to require some discussion of the scope of the welfare right to what one needs to stay alive. A welfare right of unlimited scope seems quite implausible. Fortunately for us, Brown indicates the scope of the alleged welfare right he has in mind. These are welfare rights that "most people would reject in other spheres of life". ${ }^{3}$ What are some of these supposedly bogus rights? According to Brown: "A homeless man who dies of exposure, an elderly woman whose unheated apartment precipitates a fatal case of pneumonia, an injured child who dies for want of a suitable blood transfusion would all [according to the potential future of value account] be homicide victims." 3 I doubt that Brown's account of most people's attitudes is correct. According to the decent people I know, the homeless man who dies of exposure because the community offers no warm shelter on cold nights, the elderly woman who dies because the gas company shut off her heat in winter, and the injured child who is deprived of a blood transfusion if blood of the right type is available are victims of wrongful negligence.

Brown supports his view by claiming that most people believe that we do not have the welfare right to "life-enhancing medical interventions". ${ }^{3}$ If one thinks of (much) cosmetic surgery, Brown is certainly correct. If one thinks of surgery to repair a broken hip, his claim is far from obvious.

A defender of Brown's argument strategy might argue that, in spite of Brown's very dubious claims about welfare rights, if his welfare rights argument were reformulated to apply only to fetuses, then Brown would have some good arguments for the second premise of such a revised welfare rights argument. Brown argues: "The fetus certainly needs its uterine environment if it is to realise its potential, but persons do not in general have a right to satisfy their needs at the expense of the autonomy, bodily integrity, and wellbeing of another person. If I need a bone marrow transplant in order to realise my potential future of value, I do not thereby gain a right to your bone marrow, even if you are my mother." 3

Consider the first sentence of this quotation. It might seem true because, when we think of persons "in general", we think of persons able to satisfy their 
needs on their own or with the entirely voluntary cooperation of their families. But if we consider, not persons "in general", but the population of dependent persons, matters are far less obvious. Consider the elderly with physical and mental disabilities, other people who are physically handicapped, the retarded, the mentally ill, and children. In a decent society these individuals are thought to have welfare rights that can restrict the autonomy and wellbeing of taxpayers, care-givers, children of the elderly, or parents. Thus the first sentence in the above quote, although, perhaps, technically true, does not support Brown's view of the rights of dependent human beings.

But isn't it true that a child does not have a right to her parents' bone marrow even if the bone marrow is needed for the child's survival? Perhaps there is no such present legal right, but the absence of a legal right hardly implies the absence of a corresponding moral right. There is no legal right to a minimum level of health care in the US. It obviously does not follow that someone who believes (as do I and many others) that all Americans have a moral right to a minimum level of health care is wrong. Those of us who are parents make (or have made) substantial sacrifices for our children because we believe that our children are entitled to a good upbringing. Of course, such sacrifices entail giving up some of our autonomy and well being. Furthermore, when I think of my own children, I think that my refusal to provide a needed bone marrow transplant for either of them would show that I had a seriously deficient moral character. I am willing to bet that virtually all of the readers of this essay would agree with me. Brown's account of the attitudes of most people concerning welfare rights are false.

Thus, the general version of Brown's welfare rights argument is unacceptable because Brown has not clarified and established its implausible first premise. Its second premise is false. Indeed, even if we help Brown out a bit by narrowing the welfare rights argument so that it applies only to cases of pregnancy, Brown's defence of such a restricted version of a welfare rights argument is unconvincing. In addition, Brown's welfare rights argument is subject to an even worse problem. Consider the following thought experiment. Suppose that you are very impressed with the burdens associated with welfare rights. The more impressed you are, the better reasons you will think you have for the truth of the second premise of the welfare rights argument or some first cousin of it. So far so good for Brown. However, the very same considerations make it less likely that you will think that you have good reasons for the truth of the first premise of the welfare rights argument or any first cousin of it. Accordingly, there are good reasons for thinking that the truth of both premises of the Brown's welfare rights argument or any version of it is incompatible with any doctrine of welfare rights whatsoever. Thus, Brown's welfare rights argument suffers from a major internal problem. We can conclude that Brown's argument for rejecting the potential future of value account of the wrongness of killing is subject to at least three serious problems.

\section{A consistency problem}

Brown claims that the potential future of value account of the wrongness of killing is plausible only because it is confused with a self-represented future of value account. Brown believes that a selfrepresented future of value account is plausible. ${ }^{4}$ What is a self-represented future of value? According to Brown it is created by a person who "can project a representation of a self which extends over time". "Persons care about their self-represented futures and their memories ... " "The value of a self-represented future resides with the person herself, as a feature of a richly complex mental life. Killing a person deprives her of this future: her hopes and dreams are dashed, her goals unfulfilled, her sins unforgiven, longed for reunions and reconciliations never occur."

Brown's self-represented future of value account of the wrongness of killing seems to be vulnerable to an argument obtained by altering Brown's original welfare rights argument so that it applies to self-represented futures of value. Here is the altered argument: Premise 1: If having a self-represented future of value is the basis of the right not to be killed, then human beings have a welfare right to what they need to stay alive. Premise 2: Human beings do not have a welfare right to what they need to stay alive. Conclusion: Therefore, having a self represented future of value is not the basis of the right not to be killed.

Recall that Brown defended the first premise of his original welfare rights argument by appeal to the true assertion that "[s] omeone who has been killed and someone who has been denied access to life support have been deprived equally of their potential futures". ${ }^{3}$ Apparently, someone who has been killed and someone who has been denied access to life support also have been deprived equally of their self-represented futures. Thus, if Brown's sole argument for the first premise of his welfare rights argument were good, then an equally good argument for the first premise of this altered welfare rights argument can be constructed. The second premise of this altered welfare rights argument is the same as the second premise of Brown's original welfare rights argument. Thus, even if we forget all of the problems with the welfare rights argument discussed in the previous section, it appears that Brown's overall view is subject to a serious structural problem. His own critique of the potential future of value account of the wrongness of killing can easily be altered and applied to his own self-represented future of value account of the wrongness of killing. Either that critique is sound or it is not. If it is, then Brown's self-represented future of value account of the wrongness of killing should be rejected. If it is not, then the argument he offers for rejecting the potential future of value account of the wrongness of killing is unsound. 
Apparently Brown saw this problem on the horizon and tried to avoid it. Here is one of his claims: "In contrast with potential futures, self-represented futures do not depend upon outside agencies for their realisation". "Will this do? Suppose your life depends upon a ventilator or dialysis or insulin. The realisation of your hopes, dreams, goals, that is, your self-represented future, plainly does depend upon the agency of others. Hence, Brown's claim is false.

Brown's other attempt to avoid this nasty little difficulty is to argue that: "One reason why killing persons violates their rights, but depriving them of life support need not, is that killing persons deprives them of a [self-represented] future and a past which is rightfully their own because it is something they themselves have created."4

It is hard to understand what Brown is driving at here. Persons whose lives are dependent on ventilators or dialysis can have self-represented futures they have created. Why are these futures not rightfully their own, although they would be rightfully theirs if they were not ventilator or dialysis dependent? Brown gives no argument whatsoever for his puzzling and implausible assertion. Thus Brown has failed to find a way to avoid the incompatibility between the theory of the wrongness of killing he accepts and the argument that he uses against the theory of the wrongness of killing he rejects.

There is an interesting general issue here, analysis of which will help us see the problems at the heart of Brown's discussion of futures of value. Consider the obvious. Death is the loss of life Because killing causes death, killing causes the loss of life. Killing someone causes a morally important loss. Brown's claim that "someone who has been killed and someone who has been denied access to life support have been deprived equally of their potential futures" ${ }^{3}$ is true because it is true of the loss of life in general, whatever the correct account, Brown's, mine, or another's, of exactly what it is about that loss that is morally significant. Thus, if we focus our attention only on the victim of the loss, as Brown does in the above quote, and think of why Brown's claim, limited to that focus, is true, an individual having the right not to be killed (for whatever reason) will have a welfare right to the means necessary to stay alive. There is another way of putting this point. Letting die is as bad as killing, if you consider only the consequences for the victim. Many people, especially those who believe that wrongfulness should be analysed solely in terms of the consequences of actions, have defended this so-called moral symmetry thesis, and, in my view, they are quite right to do so. ${ }^{5}$

Does this vindicate Brown's argument? Hardly. The above analysis shows why many believe that, if one considers only the victim, then all individuals having a right not to be killed also have a welfare right to be provided with what they need to stay alive. Now add Brown's claim that there is no welfare right to be provided with what one needs to stay alive. It follows that no one has the right not to be killed! Thus, if we analyse the considerations that underlie Brown's argument, we can infer, not only that it is morally permissible to kill fetuses, but that it is morally permissible to kill anyone at all, even you, me, or Brown! This is certainly a pro-choice view, although the choice is a bit more extensive than you, I, or Brown may want to accept. What went so terribly wrong?

Brown's argument strategy is subject to two problems. One is that the claim that leads from the right not to be killed to a welfare right to the means necessary to stay alive focuses exclusively on consequences. The claim that there is no welfare right to the means necessary to stay alive is typically based upon deontological considerations, that is, on the claim that the alleged duty to provide others with assistance is incompatible with one's rights to "autonomy, bodily integrity, and wellbeing" combined with the claim that considerations of rights trump considerations of welfare. ${ }^{3}$ Combining such rather different ethical perspectives arrived at independently in the same argument leads to our absurdly pro-choice view. The second is that the considerations that seem to generate so easily a welfare right to the means necessary to stay alive involve only (or primarily) the victim, not the burdens that such a welfare right may impose on others. The considerations in favour of rejecting a welfare right to the means necessary to stay alive involve emphasising the burdens of welfare on others. When different premises of the same argument presuppose such incompatible assumptions, one should not be surprised that the conclusion that can be generated is bizarre.

\section{Is the self-represented future of value account adequate?}

Nothing in the preceding analysis revealed any flaw in Brown's self-represented future of value account of the wrongness of killing. All the analysis so far has shown is that Brown's account of the wrongness of killing is incompatible with an altered welfare rights argument and a defence of that argument's premises. However, that altered welfare rights argument is unsound. Thus, both the potential future of value account and the self-represented future of value account of the wrongness of killing are compatible with the preceding analysis of this essay. If there were nothing more to be said, then the self-represented future of value account might be preferred to the potential future of value account for reasons of gender equity. This is because the wrongness of abortion would impose burdens on women that it would not impose on men and one might argue that choosing an account of the wrongness of killing that imposes such burdens on one gender, but not on the other, is unjust.

Is the self-represented future of value account of the wrongness of killing defensible? Evaluating its merit requires unpacking at least one ambiguity. At least two versions of the self-represented future of value account can be distinguished: a future version and a present version. On the future version, what underwrites the wrongness of killing is preventing the future states of which one has a present 
representation, that is, what one's self-represented future of value is a representation of, from occurring. On the present version, what underwrites the wrongness of killing is depriving someone of the present mental representations themselves of that valuable future.

Consider first the future version. Brown says: "Killing a person deprives her of her future: her hopes and dreams are dashed, her goals unfulfilled, her sins unforgiven, longed for reunions and reconciliations never occur." ${ }^{4}$

This suggests that Brown believes that killing is wrong because it prevents such future states from coming about. These future states have at least four characteristics: they are imagined by a subject; they include the subject; they are valued by the subject, and, of course, they are in the future.

Is killing wrong because it deprives someone of the actualisation of such imagined future states? Suppose Albert dreams of becoming a physician. Burt kills Albert. Albert, however, was not a diligent student, had little scientific aptitude, and would not have been admitted to medical school if he had lived. Killing Albert was certainly wrong, but it was not wrong because killing him prevented his dream of becoming a physician from being realised. His dream would not have been realised even if he had lived. Thus, in general, one cannot be deprived of a self-represented future of value to the extent that such a future of value is unrealistic. At best, only the realistic components of a self-represented future of value can underwrite the wrongness of killing.

Suppose that we modify the future version of Brown's self-represented future of value account of the wrongness of killing to avoid this difficulty. Suppose we say that depriving a person of the realistic components of a self-represented future of value underwrites the wrongness of killing. This modification clearly makes Brown's theory more plausible. However, the plausibility has a price. The realism condition is simply a way of introducing a potential future of value condition into the future version of the self-represented future of value account of the wrongness of killing. This does not look good for Brown, for the potential future of value account is the account that he wishes to reject. Brown could argue, however, that it is wrong to deprive someone of a future of value only if the future of value is both potential and selfrepresented. Because self-representation is a necessary part of the account, this realistic future version of a self-represented future of value account does not imply that abortion is wrong.

Now that a potential future of value is part of the account, is a self-represented future of value really necessary? Suppose that Alice, due to severe bipolar disease, is now unable to represent to herself any remotely desirable future of value. Is it permissible to kill Alice because she lacks a self-represented future of value? Surely not. Why not? After Alice is treated for her mental illness, Alice's life will be actually valuable to her. But now the selfrepresented future of value has dropped out of our combined potential future of value and selfrepresented future of value account of the wrongness of killing.

Other examples also show that the realistic future version of Brown's self-represented future of value account is inadequate. Consider Charles who lives only for the present and believes that thinking about one's future is a waste of time. "Eat, drink, and be merry, for tomorrow we may die" he says. Consider the adolescent who has no concept of the value of the life of anyone so old as to be over twenty-five. Surely killing both Charles and the adolescent is wrong, not only because it deprives them of the quite limited life they envisage, but because it also deprives them of the considerable span of life they (probably) will come to value. This potential future of value consideration accounts, as this version of Brown's account does not, for our belief that murder is such a major wrong.

To sum up: A simple future version of a self-represented future of value account of the wrongness of killing is too broad. To the extent that one's self-represented future is unrealistic, killing does not deprive the victim of it. A realistic future version of a self-represented future of value account is too narrow. Analysis of the problems with it leads back to the potential future of value account in which self representations are unnecessary. Apparently, all future versions of the self-represented future of value account of the wrongness of killing are less adequate than a potential future of value account.

Can a present version of the self-represented future of value account escape the difficulties with either of the future versions of that account? Brown sometimes writes as if a present version of a self-represented future of value is what he has in mind. He refers to these "mental representations, all of which are expressions of the current mental state of a self-conscious person". ${ }^{4}$ And he writes of a self-represented future of value that "All of this happens in the present, to a person able to unite in a moment of self-consciousness a personal past, present and future". When he emphasises that a self-represented future of value is something we have created, he apparently is thinking of a present mental representation, not what that representation is of. The former we create; the latter we do not necessarily create. On the present version of the self-represented future of value account, what killing wrongfully deprives one of is a present mental state, not a future state.

A simple present version of the self-represented future of value account suffers from a certain difficulty concerning time. Killing me now cannot deprive me of the mental representation I am presently having for a number of reasons. The first is that the act of killing takes time. The second is that because I am now actually having a mental representation of my future of value, that mental representation exists. What I now have, I have, whatever you do, and that is the end of it. You cannot deprive me of that. What you can now deprive me of is a mental representation I would have had 
in the immediate, or not so immediate, future. This difficulty is merely a corollary of the famous Epicurean epigram: "When I am, death is not and when death is, I am not" ${ }^{6}$ Because I cannot be deprived of my present self-represented future of value, the simple present version of the self-represented future of value account of the deprivation involved in killing is unsatisfactory.

Consider a strategy for resolving this problem. Although you cannot deprive me of the present mental representations I am now having, you can deprive me of any future mental representations, including, importantly, those of my contemplated valuable future. To accommodate this insight, we could modify a present self-represented future of value account so that it becomes a future present self-represented future of value account. Notice that, on this modification, killing us now would deprive us of (future) mental representations themselves, not what the (future) mental representations are representations of.

This future present version of the selfrepresented future of value account has a number of virtues. The self represented futures under consideration are futures of which we actually can be deprived. Furthermore, depriving us of them would, other things being equal, clearly be wrong. Nevertheless, this account has a major drawback from Brown's point of view. It does not underwrite the permissibility of abortion. Fetuses, if killed, are deprived of future self-representations of their futures of value. Accordingly, this version of Brown's self-represented future of value account of the wrongness of killing is hardly an account Brown would want to endorse.

It is worth noting that it is not an account that someone opposed to abortion should endorse either. When an oncologist informs her patient, however kindly, of a bad prognosis, she is depriving that patient of (typically many) future self representations of a future of value. Thus if the future present version of the self-represented future of value account were true, then an oncologist's candour would be almost as wrong as killing her patient. Since it is plainly not the case that an oncologist's candour is almost as wrong as killing her patients, the future present version of the self-represented future of value account is false.

In sum, Brown's self-represented future of value account of the wrongness of killing is profoundly ambiguous. It appears plausible only when different versions of the account are not distinguished. When they are teased apart, all versions of the account are implausible.

\section{Conclusion}

Brown's critique of the potential future of value argument for the wrongness of abortion is subject to many difficulties. (1) Brown has given us no good reason to accept either premise of the welfare rights argument he gives for rejecting the first premise of the potential future of value argument. (2) Any plausibility possessed by the first premise of Brown's welfare rights argument depends on an assumption that is inconsistent with the assumption needed to make the second premise plausible. (3) The account of the wrongness of killing that Brown thinks is plausible is subject to the same sort of difficulty that Brown thinks is an adequate basis for rejecting the account of the wrongness of killing that he believes is unsound. (4) Brown's selfrepresented future of value account of the wrongness of killing is ambiguous in many ways and when the ambiguities are teased apart, no credible version of the self-represented future of value account can be discovered.

This discussion has been confined entirely to critical discussion of Brown's essay, independently of broader considerations relating to the potential future of value account, welfare rights and the burdens associated with pregnancy. A better context for these broader considerations is provided by a third welfare rights argument: Premise 1: All individuals who possess whatever property it is that makes it wrong to kill them are individuals who (almost always) have a right to the means necessary to sustain their lives, if such means are available. Premise 2: Fetuses possess a property that makes it wrong to kill them. Conclusion: Therefore, fetuses (almost always) have a right to the means necessary to sustain their lives, if such means are available.

The point of the potential future of value account is to provide a basis for premise 2. Many people believe premise 1 to be true, not because they endorse the potential future of value account, but for entirely different reasons. Those who believe that the bare difference between killing and letting die is of no moral significance are often favourably inclined to something like premise 1 . There are arguments that premise 1 would garner agreement from rational individuals behind the veil of ignorance if age is also behind that veil. Many utilitarians will be favourably inclined toward premise 1. Laws requiring that critically ill patients in the US not be turned away from emergency rooms even if they cannot pay seem to presuppose premise 1.

In my view this third welfare rights argument reveals the correct analytical framework for discussion of the issues in Brown's essay. Note that, in this analytical framework, the welfare rights issue and the merits of the potential future of value account are separable. Of course, I merely waved at arguments for premise 1 in the above paragraph. On the one hand, the waves show that making the case for rejecting premise 1 is no small task. On the other hand, whether the waves can be developed into actual good arguments requires, of course, further discussion.

\section{Acknowledgement}

I thank two anonymous referees for this journal for their helpful comments.

Don Marquis, PhD is Professor of Philosophy, Department of Philosophy, The University of Kansas, Lawrence, Kansas, USA. 


\section{References and notes}

1 Marquis D. Why abortion is immoral. Fournal of Philosophy 1989;86:183-202.

Brown M. The morality of abortion and the deprivation of futures. Fournal of Medical Ethics 2000;26:103-7.

See reference 2: 104 .

4 See reference 2: 105 .
5 Steinbock B, ed. Killing and letting die. Engelwood Cliffs, NJ: Prentice-Hall, 1980. The term "moral symmetry" is Michael Tooley's, who, it should be noted, does not hold quite the same view as I do concerning abortion.

6 Epicurus. Letter to Menoeceus. In: Saunders JL, ed. Greek and Roman philosophy after Aristotle. New York: The Free Press, 1966: 49-52.

\section{News and notes \\ Death without Suffering}

An Advanced European Bioethics course, Death without Suffering, will be held from 4-6 April 2002 in Nijmegen, the Netherlands.

Subjects to be discussed include: Death, suffering and the concept of palliative care; Death and suffering: ethical perspectives; Ethical issues in pain management in hospice care, and Scientific research in palliative care.

The lecturers are: D Clark (UK), R Twycross (UK), W Dekkers, B Gordijn, $\mathrm{H}$ ten Have, D
Willems and Z Zylicz (all from the Netherlands)

The language of the course is English and the price is DFL 650 (Euro 295).

For more information please contact: $N$ Steinkamp, MA, University Medical Centre Nijmegen, Dept 232 Ethics, Philosophy \& History of Medicine, PO Box 9101, 6500 HB Nijmegen, the Netherlands. Tel: +31-24-3615320; fax: +31-243540254; e-mail: n.steinkamp@efg.kun.nl 